\title{
Immunolocalization of Ephexin-1 in the Developing Canine Cerebellum
}

\author{
Hyun Sik Park ${ }^{*}$, In Youb Chang2*, Han Yong Kim³ ${ }^{3}$ Sang Pil Yoon ${ }^{4 \#}$ \\ ${ }^{1}$ Medical Course, School of Medicine, Jeju National University, Jeju City, Republic of Korea \\ ${ }^{2}$ Department of Anatomy, College of Medicine, Chosun University, Gwangju, Republic of Korea \\ ${ }^{3}$ Department of Plastic Surgery, College of Medicine, Seonam University, Namwon, Republic of Korea \\ ${ }^{4}$ Department of Anatomy, School of Medicine, Jeju National University, Jeju City, Republic of Korea \\ Email: " spyoon@jejunu.ac.kr
}

Received 21 December 2013; revised 20 January 2014; accepted 18 February 2014

Copyright (C) 2014 by authors and Scientific Research Publishing Inc.

This work is licensed under the Creative Commons Attribution International License (CC BY).

http://creativecommons.org/licenses/by/4.0/

(c) (i) Open Access

\begin{abstract}
Ephexin-1 functions as guanine nucleotide exchange factors for the Rho-type GTPases which have important roles in neuronal development including axon guidance, migration, morphogenesis, and plasticity of neurons. As little is known about ephexin-1 in the cerebellum, we investigated the immunolocalization of ephexin-1 in the developing canine cerebellum. While the cellular maturation was followed by the temporal pattern, the calbindin D-28k and ephexin-1 immunoreactivities gradually increased in developing canine cerebellum. When compared to the calbindin D-28k immunoreactivities, belated ephexin-1 immunolocalization was observed in the Purkinje cells which aligned a single layer during cerebellar development. These results suggest that ephexin-1 might play an important role in the development of the Purkinje cells during the first two postnatal weeks based on its immunolocalization in the present study.
\end{abstract}

\section{Keywords}

Ephexin-1; Cerebellum; Purkinje Cells; Development; Dog

\section{Introduction}

Intracellular calcium-binding protein, calbindin D-28k (CB), has been used as a marker for the maturation of neurons. Information about the localization of CB in the cerebellum is also available for rats and chicks [1], primates [2], and aged dogs [3]. CB appears early shortly after cessation of mitosis when neurons become ready

\footnotetext{
*These authors equally contributed to this work.

${ }^{\#}$ Corresponding author.
} 
to start migration and differentiate [4] [5]. Previous data reported that the distribution and developmental patterns of calcium-binding proteins in the hippocampus and cerebral cortex of developing dogs were comparable to rodents and human [6] [7]. Nevertheless, anatomical and developmental studies of the canine brain are relatively scarce to date.

The features of the canine cerebellum development till $10^{\text {th }}$ postnatal week conform to the general pattern reported in the rodents and human [8]. This interspecies uniformity applies to the three cortical layers of the fully developed cerebellum as well as the immature cerebellum. Coordinated axonal guidance and neuronal migration are essential steps in this complex developmental process [9]. It is known that various guidance molecules converge on cytoskeleton regulation including ephexin-1 [10]. Ephexin-1/neuronal guanine nucleotide exchange factor (NGEF) is a novel member of the family of Dbl genes and functions as guanine nucleotide exchange factors (GEF) for the Rho-type GTPases [11]. Rho-family GTPases, which are activated by GEFs, are key regulators of cytoskeleton dynamics [12]. Extensive studies suggest that Rho GTPases have an important role in neuronal development, including axon guidance, migration, morphogenesis, and plasticity of neurons [13]-[18].

Ephexin- 1 is predominantly expressed in the brain, with the strongest signal in the caudate nucleus, a region associated with the control of movement [11]. However, no data are available that describe the immunolocalization of ephexin-1 in the cerebellum, which is concerned with the coordination of somatic motor activity and the regulation of motor tone. Therefore, the present study was designed to determine the normal maturation pattern of ephexin-1 in the developing canine cerebellum. We investigated the immunolocalization of ephexin-1 and its correlation with CB.

\section{Methods}

We limited our investigations to the period from the day of birth (P0) to P60 since neuronal development reached an adult-like pattern around the weaning period in the carnivores. The tissue sections of this study were male mongrel dogs (Canis familiaris) at P0, P7, P14, P21, P28 and P60 ( $\mathrm{n}=3$ /each). Experimental animals were anesthetized by an intraperitoneal injection of ketamine $(3 \mathrm{ml} / \mathrm{kg}$ ), fixed in Zamboni's fixative solution and processed as already described [6] [7]. All experimental procedures and care of animals were carried out in accordance with the Guidelines laid down by the NIH in the US regarding the care and use of animals for experimental procedures.

Immunohistochemical staining was carried out by the routine method. In brief, the sections were incubated overnight at $4^{\circ} \mathrm{C}$ with the primary antibody, monoclonal anti-calbindin D-28k (Sigma-Aldrich, St. Louis, MO; diluted 1:1000) or polyclonal anti-ephexin-1 (Abcam, Cambridge, MA; diluted 1:100). The binding was visualized using an appropriate ImmPRESS ${ }^{\mathrm{TM}}$ avidin-biotin-peroxidase kit (Vector laboratories, Inc., Burlingame, CA) according to the manufacturer's instructions. Peroxidase reaction was performed using $0.05 \%$ diaminobenzidine (Sigma-Aldrich). Omission of incubation with the primary or secondary antibody served as a control for false-positives.

Finally images from immunostaining were directly captured using a digital camera (PL-B873CU, PixeLINK, Ottawa, Canada) connected to a microscope (Olympus BX-51, Japan). Captured images were saved and subsequently processed using Adobe Photoshop (Adobe System, San Jose CA). The brightness and contrast were adjusted only for the purpose of background consistency of the images.

\section{Results}

Canine cerebellum showed the external granule cell layer and multiple layers of the Purkinje cells until P14. A traditional structure of the cerebellar cortex consisting of the molecular layer, the Purkinje cell layer, and the granule cell layer was achieved at P60.

An undulating band of strongly CB immunoreactive Purkinje cells could be distinguished in the developing canine cerebellum, while other layers were devoid of CB immunopositivities (Figure 1). The CB immunoreactive soma aligned multiple layers throughout the cerebellar cortex from P0 to P14. The apical dendrites of Purkinje cells were gradually arborized: reached to one-third of the cerebellar cortex at P7, two-thirds to threefourths at P14, and nearly full length at P60.

Ephexin-1 was also immunopositive in the Purkinje cells in the developing canine cerebellum (Figure 2). Contrary to CB, ephexin-1 did not ordered in multiple layers of the Purkinje cells throughout the cerebellar de- 

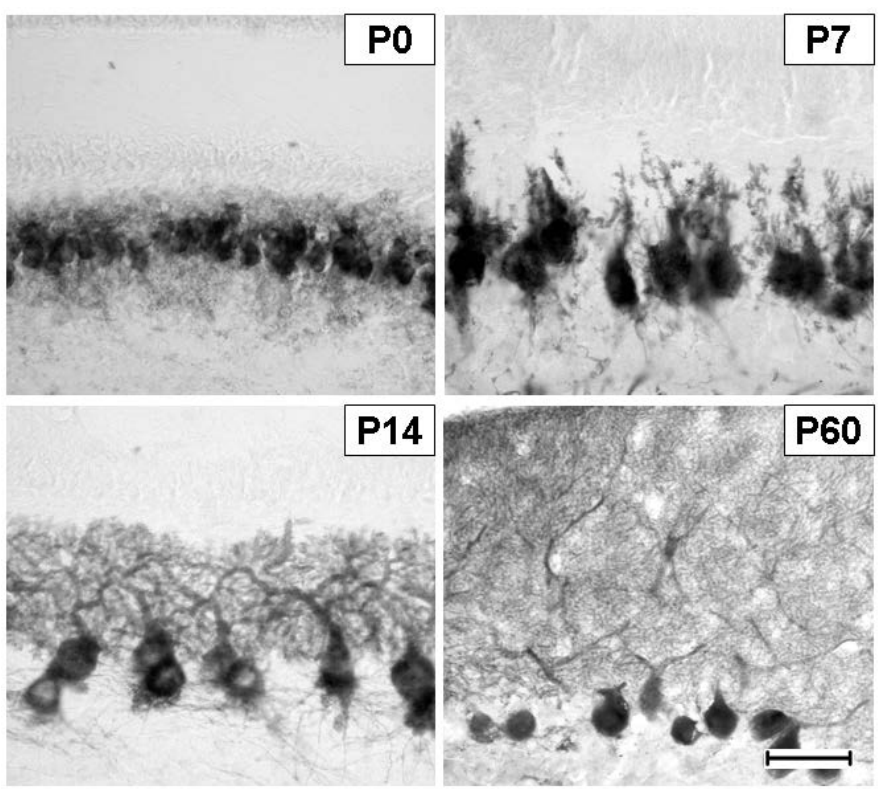

Figure 1. Calbindin D-28k (CB) immunolocalization in the developing canine cerebellum. CB immunoreactivities gradually appeared in the soma and the apical dendrites of developing Purkinje cells. Note the CB immunoreactive somata were not aligned into a single layer until P14. Scale bar $=100 \mu \mathrm{m}$.

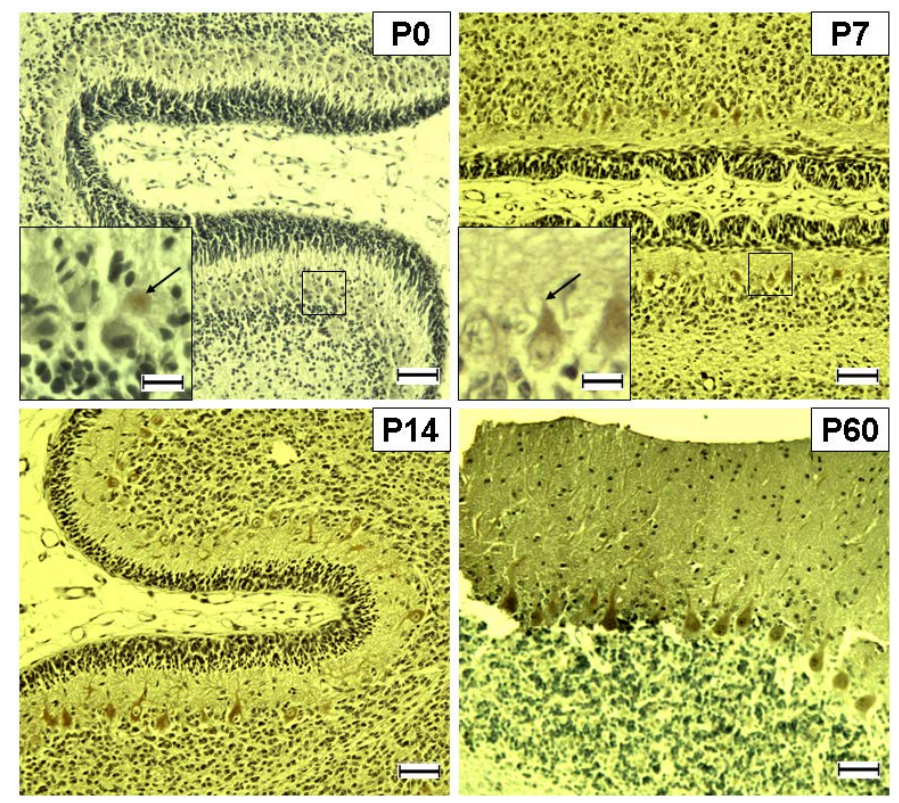

Figure 2. Ephexin-1 immunolocalization in the developing canine cerebellum. Ephexin-1 immunoreactivity was rarely observed in the soma (arrow in P0) of the Purkinje cell at birth, and then in the apical dendrites (arrow in P7) as the dendritic arborization was being matured. Contrary to $\mathrm{CB}$, the ephexin-1 immunoreactive soma aligned into a single layer throughout the experimental period. Scale bar $=100 \mu \mathrm{m} ;=25 \mu \mathrm{m}$ for rectangles in A and B.

velopment. Ephexin-1 immunolocalization was rarely observed in the cerebellar cortex at P0. There was an only evidence of ephexin-1 having very weak immunopositivity in the cytoplasm of a Purkinje cell. Ramified cell 
processes could be seen leaving the apical portion of the perikarya of the ephexin-1 immunopositive Purkinje cells at P7. The apical dendrites of Purkinje cells reached two-thirds to three-fourths of cerebellar cortex at P14. At P60, ephexin-1 immunopositivities were mainly seen in the somata and proximal apical dendrites of the Purkinje cells.

\section{Discussion}

While the cellular maturation was followed by the temporal pattern, CB and ephexin- 1 immunoreactivities gradually increased in developing canine cerebellum. CB immunoreactive Purkinje cells aligned multiple layers from P0 to P14, but belated ephexin-1 immunolocalization ordered in a single layer of the Purkinje cells throughout the cerebellar development. Adult-like immunolocalization of CB and ephexin-1 was achieved at P28, which was sustained until P60 in developing canine cerebellum.

We used CB as a marker for the Purkinje cells [19] to better follow the development of the Purkinje cells and localize ephexin-1 immunostaining. The distribution and developmental patterns of calcium-binding proteins in the canine central nervous system were comparable to rodents and primates [6] [7] including this study. CB immunoreactivity was seen in most of the canine brain and their adult-like distribution was achieved around the weaning period. Siso et al. [3] showed that CB was immunopositive only in the cerebellum of aged dogs and that the climbing fibers from the inferior olivary nuclei were completely devoid of CB immunoreactivity. The finding by Siso et al. [3] is peculiar since a major impact on Purkinje cell calcium homeostasis is mediated by climbing fiber-type afferents originating from the inferior olivary nuclei [20].

Careful attention must be paid to the fact of cerebellar development until P14. The immunostaining patterns of several markers appear and peak around the second postnatal week as described in a previous report [19]. Parvalbumin, another calcium-binding protein, labeling was observed initially in the soma and extending gradually to the dendritic arborization later than $\mathrm{CB}$, which was in parallel with an increase in neuronal activity including synaptogenesis [4] [5] [21]. Proper dendritic arborization of Purkinje cells is thought to be a prerequisite for cerebellar motor coordination. Actin dynamics shapes the postnatal arborization of Purkinje cells with the maturation of the actin nucleator, Cobl [22]. In this context, the immunolocalization of ephexin-1 during the first and second postnatal weeks indicates that it may play a critical role in the early development of the Purkinje cells. When differentiating morphologically and becoming immunoreactive for ephexin-1, Purkinje cells during postnatal development may promote the stability of synaptic activity as suggested by Oostland and van Hooft [23].

Ephexin-1 acts as GEF for multiple RhoA family GTPases [18] [24]. Ephexin-1 activates RhoA and Cdc42, but only weakly activates Rac. In response to ephrin-A ligand, ephexin activates RhoA, in turn, activates Rho kinase. Via activation of RhoA, ephexin-1 is an important regulator for the axon guidance of retina ganglion cells during early development of synapse formation, and modulates both the localization of neurotransmitter receptors and the postsynaptic structure remodeling in the dendritic spines of the hippocampal neurons. Via activation of Cdc42, ephexin-1 regulates the homeostatic synaptic vesicle release, and may function to control cytoskeletal dynamics downstream from attractant receptors through p21q-activated kinase activation. Ephexin-1 knockout mice did not reveal overt defects in retinogeniculate and retinocollicular projections [17]. It can be explained by the lack of a prominent in vivo phenotype of ephexin-1 proteins.

Nevertheless, one of the main roles of ephexin-1 is the regulation of cytoskeletal changes [25]. The present study provides the first information on the immunolocalization of ephexin- 1 in the developing canine cerebellum. Ephexin-1 expressed by the dendritic arborization of the Purkinje cells might have a specialized role during postnatal development of canine cerebellum, and should be examined by further experiments.

\section{Acknowledgements}

This research was supported by the National Research Foundation of Korea (NRF), funded by the Ministry of Science, ICT, and Future Planning (NRF-2011-0018686).

\section{Conflict of Interest}

None declared. 


\section{References}

[1] Roger, J.H. (1989) Immunoreactivity for Calretinin and Other Calcium-Binding Proteins in Cerebellum. Neuroscience, 31, 711-721. http://dx.doi.org/10.1016/0306-4522(89)90435-1

[2] Fortin, M., Marchand, R. and Parent, A. (1998) Calcium-Binding Proteins in Primate Cerebellum. Neuroscience Research, 30, 155-168. http://dx.doi.org/10.1016/S0168-0102(97)00124-7

[3] Siso, S., Tort, S., Aparici, C., Perez, L., Vidal, E. and Pumarola, M. (2003) Abnormal Neuronal Expression of the Calcium-Binding Proteins, Parvalbumin and Calbindin D-28k, in Aged Dogs. Journal of Comparative Pathology, 128, 9-14. http://dx.doi.org/10.1053/jcpa.2002.0597

[4] Celio, M.R. (1990) Calbindin D-28k and Parvalbumin in the Rat Nervous System. Neuroscience, 35, 375-475. http://dx.doi.org/10.1016/0306-4522(90)90091-H

[5] Bastianelli, E. (2003) Distribution of Calcium-Binding Proteins in the Cerebellum. Cerebellum, 2, 242-262. http://dx.doi.org/10.1080/14734220310022289

[6] Yoon, S.P., Chung, Y.Y., Chang, I.Y., Kim, J.J., Moon, J.S. and Kim, H.S. (2002) Postnatal Development of Calbindin D-28k and Parvalbumin Immunoreactivities in the Canine Hippocampus. Journal of Chemical Neuroanatomy, 19, 143-154. http://dx.doi.org/10.1016/S0891-0618(00)00059-4

[7] Moon, J.S., Kim, J.J., Chang, I.Y., Chung, Y.Y., Jun, J.Y., You, H.J. and Yoon, S.P. (2002) Postnatal Development of Calbindin D-28k and Parvalbumin Immunoreactivities in the Canine Anterior Cingulated Cortex: Transient Expression in Layer V Pyramidal Cells. International Journal of Developmental Neuroscience, 20, 511-519. http://dx.doi.org/10.1016/S0736-5748(02)00056-4

[8] Phemister, R.D. and Young, S. (1968) The Postnatal Development of the Canine Cerebellar Cortex. Journal of Comparative Neurology, 134, 243-253. http://dx.doi.org/10.1002/cne.901340209

[9] Ayala, R., Shu, T. and Tsai, L.H. (2007) Trekking across the Brain: The Journey of Neuronal Migration. Cell, 128, 29-43. http://dx.doi.org/10.1016/j.cell.2006.12.021

[10] Peng, Y.J., He, W.Q., Tang, J., Tao, T., Chen, C., Gao, Y.Q., Zhang, W.C., He, X.Y., Dai, Y.Y., Zhu, N.C., Lv, N., Zhang, C.H., Qiao, Y.N., Zhao, L.P., Gao, X. and Zhu, M.S. (2010) Trio Is a Key Guanine Nucleotide Exchange Factor Coordinating Regulation of the Migration and Morphogenesis of Granule Cells in the Developing Cerebellum. The Journal of Biological Chemistry, 285, 24834-24844. http://dx.doi.org/10.1074/jbc.M109.096537

[11] Rodrigues, N.R., Theodosiou, A.M., Nesbit, M.A., Campbell, L., Tandle, A.T., Saranath, D. and Davies, K.E. (2000) Characterization of Ngef, a Novel Member of Dbl Family of Genes Expressed Predominantly in the Caudate Nucleus. Genomics, 65, 53-61. http://dx.doi.org/10.1006/geno.2000.6138

[12] Jaffe, A.B. and Hall, A. (2005) Rho GTPases: Biochemistry and Biology. Annual Review of Cell and Developmental Biology, 21, 247-269. http://dx.doi.org/10.1146/annurev.cellbio.21.020604.150721

[13] Luo, L. (2000) Rho GTPases in Neuronal Morphogenesis. Nature Reviews. Neuroscience, 1, 173-180. http://dx.doi.org/10.1038/35044547

[14] Wong, K., Ren, X.R., Huang, Y.Z., Xie, Y., Liu, G., Saito, H., Tang, H., Wen, L., Brady-Kalnay, S.M., Mei, L., Wu, J.Y., Xiong, W.C. and Rao, Y. (2001) Signal Transduction in Neuronal Migration: Roles of GTPase Activating Proteins and the Small GTPase Cdc42 in the Slit-Robo Pathway. Cell, 107, 209-221. http://dx.doi.org/10.1016/S0092-8674(01)00530-X

[15] Klein, R. (2004) Eph/Ephrin Signaling in Morphogenesis, Neural Development and Plasticity. Current Opinion in Cell Biololgy, 16, 580-589. http://dx.doi.org/10.1016/j.ceb.2004.07.002

[16] Govek, E.E., Newey, S.E. and Van Aelst, L. (2005) The Role of the Rho GTPases in Neuronal Development. Genes \& Development, 19, 1-49. http://dx.doi.org/10.1101/gad.1256405

[17] Murai, K.K. and Pasquale, E.B. (2005) New Exchanges in Eph-Dependent Growth Cone Dynamics. Neuron, 46, 161163. http://dx.doi.org/10.1016/j.neuron.2005.04.004

[18] Shi, L., Fu, A.K. and Ip, N.Y. (2010) Multiple Roles of the Rho GEF Ephexin1 in Synapse Remodeling. Communicative \& Integrative Biology, 3, 622-624. http://dx.doi.org/10.4161/cib.3.6.13481

[19] Chang, I.Y., Ohn, T., Ko, G.S., Yoon, Y., Kim, J.W. and Yoon, S.P. (2012) Immunolocalization of Steroidogenic Acute Regulatory Protein-Related Lipid Transfer (START) Domain-Containing Proteins in the Developing Cerebellum of Normal and Hypothyroid Rats. Journal of Chemical Neuroanatomy, 43, 28-33. http://dx.doi.org/10.1016/j.jchemneu.2011.10.003

[20] Tolbert, D.L. and Clark, B.R. (2000) Olivocerebellar Projections Modify Hereditary Purkinje Cell Degeneration. Neuroscience, 101, 417-433. http://dx.doi.org/10.1016/S0306-4522(00)00362-6

[21] Simat, M., Ambrosetti, L., Lardi-Studler, B. and Fritschy, J.M. (2007) GABAergic Synaptogenesis Marks the Onset of 
Differentiation of Basket and Stellate Cells in Mouse Cerebellum. The European Journal of Neuroscience, 26, 22392256. http://dx.doi.org/10.1111/j.1460-9568.2007.05846.X

[22] Haag, N., Schwintzer, L., Ahuja, R., Koch, N., Grimm, J., Heuer, H., Qualmann, B. and Kessels, M.M. (2012) The Actin Nucleator Cobl Is Crucial for Purkinje Cell Development and Works in Close Conjunction with the F-Actin Binding Protein Abp1. The Journal of Neuroscience, 32, 17842-17856. http://dx.doi.org/10.1523/JNEUROSCI.0843-12.2012

[23] Oostland, M. and van Hooft, J.A. (2013) The Role of Serotonin in Cerebellar Development. Neuroscience, 248C, 201-212. http://dx.doi.org/10.1016/j.neuroscience.2013.05.029

[24] Schmucker, D. and Zipursky, S.L. (2001) Signaling Downstream of Eph Receptors and Ephrin Ligands. Cell, 105, 701-704. http://dx.doi.org/10.1016/S0092-8674(01)00391-9

[25] Rosas, O.R., Figueroa, J.D., Torrado, A.I., Rivera, M., Santiago, J.M., Konig-Toro, F. and Miranda, J.D. (2011) Expression and Activation of Ephexin Is Altered after Spinal Cord Injury. Developmental Neurobiology, 71, 595-607. http://dx.doi.org/10.1002/dneu.20848 